\title{
Neuropsychology and advances in memory function
}

\author{
B. Gordon
}

\author{
Departments of Neurology and Cognitive Science, The Johns Hopkins University, \\ Cognitive Neurology/Neuropsychology and The Memory Clinic, Meyer 222, \\ The Johns Hopkins Hospital, 600 N. Wolfe St., Baltimore, MD 21287-7222, USA
}

Recent developments in the functional and neural bases of several aspects of memory are described including long term cortical memory storage, the transition from immediate to permanent memory mediated by medial temporal structures, working memory, memory retrieval, and implicit memory. These are linked to current data on the nature of anterograde and retrograde amnesia in the degenerative diseases, and also to issues in the clinical diagnosis of memory impairments. Understanding the bases of memory can inform the diagnosis of memory impairments in degenerative diseases, and the patterns of impairment seen in the degenerative diseases can help contribute to knowledge of the mechanisms of normal memory.

This article originally appeared in a modified form in Current Opinion in Neurology (1997), 10, 306-312.

\section{INTRODUCTION}

Perry and Hodges (1996) focused on the different profiles of memory dysfunction in different degenerative diseases. This review of progress will focus on advances in understanding the components of memory function (and dysfunction) and will touch on the implications these may have for understanding, diagnosing, and treating the memory disorders caused by degenerative diseases.

Recent progress has emphasised several old lessons. Memory is the persistence of information. Mechanisms for the persistence of information appear to be broadly distributed throughout the nervous system, as would be expected for so basic a need. At every level in each neuronal processing stream, there appears to be mechanisms that can extend the duration of neural activity, or that work to ensure that the information carried by transient neural activity can be stored. This more permanent storage is long term memory at the neural level. It seems clear that entrapment of transient neural activity into long term, neural memory is not a single step, but itself entails a large number of different processes. Each of these different steps to permanence themselves have their own particular time scales and mechanisms, and perhaps regional differences as well (Castro-Alamacos and Connors, 1997). The fastest are biochemical; perhaps the slowest are neural sprouting and remodelling. Neural remodelling may continue into adulthood in mammals, and may be brought on by experience (Kemperman et al., 1997).

It is clear, therefore, that 'memories' may result from many different levels of nervous system function (e.g. DNA, synaptic, neural, and neural network), and from many different types of processes even within each level (e.g. transient versus more permanent changes in synaptic reactivity). There have been a number of attempts to carve this complexity into a basis set of theoretically meaningful categories and relationships between them. This review discusses results within a few of these categories. However, it should be appreciated that the boundaries between these categories are not always clear, and are subject to empirical and theoretical redrawing (Robbins, 1996; Eichenbaum, 1997; Mathews, 1997). Moreover, normal circumstances of learning and recall may engage several different memory systems at the same time (Thompson and Kim, 1996).

\section{PERMANENT STORAGE OF INFORMATION AND THE EFFECTS OF DEGENERATIVE DISEASES}

It is now widely assumed, with mounting evidence, that information is stored in essentially the same regions of the nervous system in which it is used. Hence, much of the information ordinarily considered important to 
people - such as facts within language, knowledge of pictures and faces - is cortically stored in the specific regions or combinations of specific regions responsible for the underlying functions. This has been particularly well worked out in the case of primate vision and visual representations, as Ungerleider (1995) reviewed.

The effects of degenerative diseases upon these cortical regions are often treated as though they were focal lesions (albeit widespread focal lesions). This is often correct, at least to a first approximation [e.g. in the case of posterior cortical atrophy (Ardila et al., 1997) or focal-onset Alzheimer's disease (Davous et al., 1996)] but there are also many reasons why degeneration affecting a region may have different effects from a structural lesion of the same region. Degenerative conditions evolve over much longer periods of time. This slow evolution may allow the individual to develop functional and possibly neuroanatomic compensations. Some evidence for this has been found in Alzheimer's disease (Becker et al., 1996).

At a more basic level, however, degenerative diseases may alter how the affected cortex processes information compared with the changes produced by structural lesions. Warrington and Cipolotti (1996) suggested this possibility in the context of trying to understand impairments of semantic representations. Warrington and Cipolotti pointed out that degenerative diseases (and also herpes encephalitis) have been associated with total loss, or partial degradation, of semantic representations (1996). In partial contrast, semantic representations may not be lost with focal lesions, but instead may be refractory to access, particularly at rapid rates of stimulation. Why this difference should occur is not clear, although there are many possible local mechanisms (for example, degenerative diseases may affect only subpopulations of neurons). Regardless, investigators need to exercise caution in treating degenerations as though they were focal lesions. This also suggests a new opportunity, however. Degenerative diseases may cleave neuronal processes in ways that other diseases or techniques cannot.

\section{PERMANENT STORAGE OF DECLARATIVE INFORMATION}

There is now general agreement that the hippocampus and related medial temporal structures mediate the translation of temporary cortical activity (for some material) into more permanent forms of storage in the cortex. There is, it must be admitted, marked disagreement about exactly what types of information are involved, what parts of the hippocampus and adjacent structures are actually doing what, and how long this consolidation process takes (Hasselmo, 1994; Gluck, 1996; Granger et al., 1996; Hasselmo et al., 1996; McClelland and Goddard, 1996; Gluck et al., 1997). However, the importance of the hippocampus and adjacent medial temporal structures in the general process of immediate to permanent translation cannot be doubted. Traditionally, much of the evidence for this role has come from lesion studies. A particularly illustrative lesioned case was reported by Broman et al. (1997). The authors described a 27-year-old who developed a severe anterograde amnesia caused by respiratory arrest at the age of 8 years. Magnetic resonance imaging showed damage limited to the hippocampal region bilaterally, as would be expected from the history. It was not just new learning of episodic information that was severely impaired; this patient's development of vocabulary, literacy, and some other language functions were also arrested by his deficit. This case reinforces the points noted earlier, that current categorizations of memory systems may be imperfect, and that real life learning situations may require the cooperation of several different memory systems.

The role of the medial temporal structures in new learning has also now been demonstrated in vitro, by functional imaging with position emission tomography (Nyberg et al., 1996) and functional magnetic resonance imaging (Stern et al., 1996; Gabrielli et al., 1997).

The prominent, early involvement of medial temporal structures by many degenerative conditions, such as Alzheimer's disease, is presumably part of the basis for the marked deficits of new learning (anterograde amnesia) in these conditions. Atrophy of the hippocampal formation (as measured by magnetic resonance imaging) predicts decline in memory function in ageing (Golomb et al., 1996). In addition, many degenerative conditions cause other damage that would be expected to potentiate the effects of the medial temporal involvement. Disruption of cholinergic output from the nucleus basalis could impair an important cortical learning mechanism (Bakin and Weinberger, 1996). The medial temporal region is also likely to be important in memory retrieval (Gabrielli et al., 1997). The joint disruption of both new learning and retrieval may account for why memory testing that jointly assesses both memory components may be more sensitive and specific for Alzheimer's disease than more narrowly focused memory testing (Buschke et al., 1997).

\section{WORKING MEMORY}

Working memory is the term now applied to the scratchpad capabilities that allow new and old 
information to be briefly retained in active, manipulable form. In this formulation, working memory is not so much a memory system as it is a confederation of already existing memory and executive abilities, which are recruited to suit the task at hand. Interest in and investigation of working memory has exploded in recent years, in part because of its clear importance as the conduit for learning, recall, and reasoning and many other mental abilities (Conway and Engle, 1996; Goldman-Rakie, 1996; Goldman-Rakie, 1997), and in part because it has proven to be accessible to neuroimaging and electrophysiologic techniques (D’Esposito et al., 1995; Baddeley, 1996; Cohen et al., 1997; Courtney et al., 1997; Ruchkin et al., 1997).

Working memory clearly requires activation not only of the regions directly involved in memory storage, but also of multiple prefrontal regions that are probably involved in memory search, coordination, and temporary storage of information and intermediate byproducts of processing.

Degenerative diseases, because of their typically widespread cerebral involvement, would be expected to cause early, marked impairments in working memory capacities. Working memory impairments, in turn, may underly some of the puzzling clinical presentations of these conditions. A recent study that may be related to this point examined the effects of talking while walking in ageing and Alzheimer's disease (Camicioli et al., 1997). The speed of walking in individuals with Alzheimer's disease slowed more when they talked at the same time than did the speed of aged individuals. This, it was suggested, may contribute to the risk of falls in Alzheimer's disease.

\section{MEMORY RETRIEVAL}

To be useful, information must not only be stored; it must also be accessed. Access can take the form of recognition, which is theoretically fairly direct, in the same regions where the memory is stored. Or it can involve recall, which may be by part-whole cueing, associative cues, time tags, or other mechanisms for recreating the stimulus that was originally encoded. Recall in particular, therefore, could often be expected to require many brain regions, and perhaps a relatively long time period of iterative activity. Functional imaging has to some extent supported these notions, showing activation of posterior as well as prefrontal regions with recall (Fletcher et al., 1997; Cabeza et al., 1997). However, as lesion data had already suggested, neuroimaging studies have also shown that medial temporal structures play a role in memory retrieval (Fletcher et al., 1997; Gabrielli et al., 1997; Nyberg et al., 1996). As noted above, the dual role of medial temporal structures in new learning and in memory retrieval may account for the magnitude of the memory impairments seen in degenerative conditions that affect these regions.

\section{REMOTE MEMORY}

Classically, memory for premorbid information in degenerative conditions with memory loss was described by Ribot's law (Ribot, 1881): the retrograde amnesia was more marked for more recent past events and knowledge, and less marked (if a problem at all) for the oldest remote memories. This description is now known to be too simplistic, empirically inaccurate, and theoretically contentious. Many different categories of remote knowledge have been distinguished, although the fundamental reasons why there should be distinctions between them (if any) are not always clear. Semantic memory, memory for famous faces, famous names, external events, and memory for personal information (what some categorise as autobiographical memory) have all been studied, both in the degenerative diseases (Greene and Hodges, 1996) and in other conditions (Barbarotto et al., 1996; Campodonico and Rediess, 1996; Evans et al., 1996; Markowitsch, 1996; Alexander, 1997; Schmidtke and Vollmer, 1997; Reinkemeier, 1997) including normal ageing (Jansari and Parkin, 1996). Widespread regions of the brain, particularly of the right hemisphere, are activated in response to personal autobiographical information (Fink et al., 1996). Retrieval of semantic information is also associated with activation of many brain regions, with some differences found for types of items (Damasio et al., 1996).

One reason the study of retrograde amnesia has become so active is that the nature and extent of retrograde amnesia helps test different theories of memory storage (Graham and Hodges, 1997; Snowden et al., 1996; Kapur, 1997; Murre, 1997). In the modal theory of memory described earlier, information is initially processed in the cortex. Long term retention of that information in the cortex is dependent (in some fashion) upon the hippocampus and other medial temporal structures. For some variable period of time after initial exposure, cortical memories remain susceptible to fading or disruption. This disruption is prevented by the medial temporal lobe system(s). Hence, in this formulation, damage to the medial temporal lobe will not only prevent the formation of new memories, but also allow the dissipation of more recent old memories; the fate of old memories of different ages will show how long is required for the fixation process. Conversely, 
direct damage to the cortical storage system should damage all memories dependent upon cortical storage alone (older old memories), but comparatively spare more recent old memories, which are still being supported by the hippocampal system. Such a dissociation was found by Graham and Hodges (1997) between the retrograde gradients caused by amnestic Alzheimer's disease (presumably, a variant with degeneration more limited to the medial temporal lobe) and that caused by semantic dementia (having, among other problems, a fluent aphasia probably caused by cortical degeneration of the temporal lobe).

\section{IMPLICIT MEMORY}

Implicit memory is the term applied to learning and memory that does not require an explicit statement, but which is revealed in the course of performance of a task. Examples include the ability to detect perceptually degraded pictures or words, or learning of a motor skill such as maze navigation. It is likely that implicit memory is not a memory system per se, but instead a common characteristic of a large number of different neural systems, which show a common ability to learn through repetition. As expected from this formulation, implicit learning is not dependent upon the medial temporal (hippocampal) system, but instead dependent upon the specific regions involved in the function. Visuoperceptual implicit memory, for example, has been shown to be impaired in a patient with bilateral occipital lobe lesions (Keane et al., 1995); learning a probabilistic classification was severely impaired in Parkinson's patients, but not in amnestic patients (Knowlton et al., 1996).

Traditionally, implicit memory was not affected by Alzheimer's disease, although deficits in implicit memory (motor skill learning) could be found in another degenerative disease, Huntington's chorea (Knopman and Nissen, 1991). However, more recent studies have suggested deficits in abilities such as perceptual fluency in Alzheimer's disease, although there are considerable conceptual difficulties in comparing the 'degree' of learning across patient and control groups (Gordon, 1988). Regardless, d-cycloserine, which affects the $N$-methyl-D-aspartate subtype of the central nervous system glutamate receptor, has recently been shown to improve priming in a word identification task in Alzheimer's disease patients (Schwartz et al., 1996). Deficits in implicit memory would be expected in a disease which directly affects the circuits responsible, as Alzheimer's disease quite plausibly could do. The Schwartz et al. finding is among the accumulating evidence that the efficiency of these circuits can be enhanced by $N$-methyl-D-aspartate receptor modulation.

\section{EDUCATION, ABILITY AND THE COURSE OF DEGENERATIVE DISEASE}

As expected, higher education and ability can affect the presentation of conditions such as Alzheimer's disease. Higher levels of education are associated with higher levels of functioning on verbal measures in Alzheimer's disease, but not with nonverbal measures, as a study by Filley and Cullum (1997) recently confirmed. What has captured public interest is the possibility that higher levels of education and accomplishment in some way protect against the development or expression of the disease. This has been the conclusion reached from a study of nuns (Snowdon $e t$ al., 1996) and from a large, community-based sample of African-Americans (Callahan et al., 1996), among others. However, a fundamental flaw of both these studies was that the criteria for intellectual impairment (performance) for the diagnosis of dementia were the same across all education and ability levels; they were not themselves adjusted for premorbid intellectual ability. Even if the decline caused by Alzheimer's disease was independent of ability, higher premorbid ability will cause an apparent delay in reaching such criteria because the individual is starting from a higher level, as the Filley and Cullum (1997) study and other data suggest they should. Therefore, although there are many reasons to think that early and sustained intellectual activity is desirable for maintaining mental abilities in later life, there is no reliable evidence, as yet, that it can truly protect against the onslaught of a devastating condition such as Alzheimer's disease.

\section{CLINICAL DETECTION}

The degenerative diseases do not generally result in qualitative neuropsychologic differences from normal ageing, at least in their early stages (although it would be hoped that they would). Instead quantitative differences from normal memory and other neuropsychologic functions are more often found. Self reported complaints, the observations of family and friends, and the health care provider's suspicions and mental status testing are the three principal routes to detection of Alzheimer's disease and other dementing conditions.

\section{Self reported problems}

Self reported problems with memory and other mental abilities unfortunately usually correlate with depression rather than degenerative disease, as one recent 
(Smith et al., 1996) and many previous studies continue to demonstrate. Subjective complaints do sometimes presage development of dementia (Schmand et al., 1996), as expected. Moreover, in nondepressed individuals, subjective memory complaints do correlate with actual memory performance (Jonker et al., 1996). This correlation may be expected to lessen with individuals who have more definite disease, such as early Alzheimer's disease, because of the minimization or complete unawareness of problems (agnosagnosia) that is often a feature of this condition. Starkstein et al. (1996) drew a further distinction, between unawareness of deficits in memory, orientation, reasoning, and praxis (cognitive unawareness), and unawareness for irritability, selfishness, inappropriate emotionality, and disinhibition (behavioral unawareness). Behavioral unawareness was present early in the disease; cognitive unawareness was more likely later.

\section{Family informants}

Family reports have long been the mainstay of detection of dementia, with generally a high sensitivity and an inherent ability to correct for premorbid intelligence and education (Mulligan et al., 1996). However, the false-negative rate of family informants can be appreciable. Problems with 'memory or thinking' were denied by family informants in $21 \%$ of elderly Japanese-American men who met criteria for dementia (Ross et al., 1997). This was particularly true with borderline or very mild dementia (52\%), and less likely with more definite dementia (13\%). However, as the authors of this study pointed out, these percentages may be greater than those found in other populations (Ross et al., 1997). Respect for the elderly and the social stigmatism of mental illness in this cultural group would have been expected to inflate the percentage of unrecognised dementia, as would the fact that this cohort of elderly Japanese-American men was typically not expected to do many of the daily household duties that might have more easily revealed their cognitive deficits.

\section{Clinical detection}

Given the relatively high frequency of Alzheimer's disease, and the prominence of memory deficits, relatively short mental status tests that focus on memory are often sensitive enough for clinical screening (Stuss et al., 1996). This is also true in examining the subset of individuals who present with memory loss, and who are at risk of developing Alzheimer's disease, with its more florid memory impairments (Tierney et al., 1996). However, more complete neuropsychologic evaluation is likely to be desirable in clinical settings where the spectrum of presenting conditions is wider, and where the risks of individual false positives and false negatives must be kept as low as possible (Selnes, 1995). Crystal and colleagues (1996) used formal neuropsychometnc test data, both cross sectionally and longitudinally, to assess a sample of originally nondemented older individuals. Level of performance at entry, and rate of change, were both important predictors of ultimate normality, pathologic ageing, or Alzheimer's disease. These data would have been unreliable or unavailable from shorter screening instruments.

\section{CONCLUSION}

Analysis of memory deficits in degenerative disease is clearly an ongoing process, and rewarding for a number of reasons. There is the constant refinement of our understanding of what comprise 'memory' deficits, both quantitative and qualitative, which allows these conditions to be differentiated from normal ageing, and from each other. More detailed knowledge of the neuropsychology and underlying pathophysiology will allow more rational and more effective therapies for these conditions. Knowledge of the deficits that occur in degenerative diseases may also help to refine knowledge of the processes and neuroanatomic substrates necessary for normal cognitive and memory functions.

\section{Acknowledgements}

Preparation of this review was supported in part by the Benjamin A. Miller Family Fund for Alzheimer's Disease and Related conditions.

\section{REFERENCES}

Alexander MP (1997) Specific semantic memory loss after hypoxic-ischemic injury. Neurology, 48, 165-173.

Ardila A, Rosselli M, Arvizu L and Kuljis RO (1997) Alexia and agraphia in posterior cortical atrophy. Neuropsychiatry, Neuropsychology and Behavioural Neurology, 52.

Baddeley A (1996) The fractionation of working memory. Proceedings of the National Academy of Sciences USA, 93, 13468-13472.

Bakin JS and Weinberger NM (1996) Induction of a physiological memory in the cerebral cortex by stimulation of the nucleus basalis. Proceedings of the National Academy of Sciences USA, 93, 11219-11224.

Barbarotto R, Laiacona M and Cocchini G (1996) A case of simulated, psychogenic or focal pure retrograde amnesia: did an entire life become unconscious? Neuropsychologia, 34, 575-585.

Becker JT, Mintun MA, Aleva K, Wiseman MB, Nichols T and Dekosky ST (1996) Compensatory reallocation of brain resources supporting verbal episodic memory In Alzheimer's disease. Neurology, 46, 692-700. 
Broman M, Rose AL, Hotson C and Casey CM (1997) Severe anterograde amnesia with onset In childhood as a result of anoxic encephalopathy. Brain, 120, 417-433.

Buschke H, Sliwinski MJ, Kuslansky G and Lipton RB (1997) Diagnosis of early dementia by the Double Memory Test: encoding specificity Improves diagnostic sensitivity and specificity. Neurology, 48, 989-997.

Cabeza R, Kapur S, Craik FIM, McIntosh AR, Houle S and Tulving E (1997) Functional neuroanatomy of recall and recognition: a PET study of episodic memory. Journal of Cognitive Neuroscience, 9, 254-265.

Callahan CM, Hall KS, Hui SL, Musick BS, Unverzagt FW and Hendrie HC (1996) Relationship of age, education, and occupation with dementia among a communitybased sample of African Americans. Archives of Neurology, 53, 134-140.

Camicioli R, Howieson D, Lehman S and Kaye J (1997) Talking while walking: the effect of a dual task in aging and Alzheimer's disease. Neurology, 48, 955-958.

Campodonico JR and Rediess S (1996) Dissociation of implicit and explicit knowledge In a case of psychogenic retrograde amnesia. Journal of the International Neuropsychological Society, 2, 146-158.

Castro-Alamacos MA and Connors BW (1997) Distinct forms of short-term plasticity at excitatory synapses of hippocampus and neocortex. Proceedings of the National Academy of Science of USA, 94, 4161-4166.

Cohen JD, Perlstein WM, Braver TS, Nystrom LE, Noll DC, Jonides J and Smith EE (1997) Temporal dynamics of brain activation during a working memory task. Nature, 386, 604.

Conway ARA and Engle RW (1996) Individual differences in working memory capacity: more evidence for a general capacity theory. Memory, 4, 577-590.

Courtney SM, Ungerleider LG, Keil K and Haxby JV (1997) Transient and sustained activity in a distributed neural system for human working memory. Nature, 386, 608-611.

Crystal HA, Dickson D, Sliwinski I, Masur D, Blau A and Lipton RB (1996) Associations of status and change measures of neuropsychological function with pathologic changes in elderly. Archives of Neurology, 53, 82-87.

D'Esposito M, Detre J, Alsop D, Shin R, Atlas S and Grossman M (1995) The neural basis of central executive system of working memory. Nature, 378, 279-281.

Damaslo H, Grabowski TJ, Tranel D, Hichwa RD and Damasio AR (1996) A neural basis for lexical retrieval. Nature, 380, 499-505.

Davous F, Panisset M, De Agostin M and Boller F (1996) Visuo-spatial dysgnosia and Balint's syndrome as major symptoms of probable Alzheimer's disease. European Journal of Neurology, 3, 519-527.

Eichenbaum H (1997) Memory: old questions, new perspectives. Current Biology, 7, R53-R55.

Evans JJ, Breen EK, Antoun N and Hodges JR (1996) Focal retrograde amnesia for autobiographical events following cerebral vasculitis: a connectionist account. Neurocase, 2, 1-12.

Filley CM and Cullum CM (1997) Education and cognitive function in Alzheimer's disease. Neuropsychiatry Neuropsychology and Behavioural Neurology, 10, 48-51.

Fink GR, Markowitsch HJ, Reinkemeier M, Bruckbauer T, Kessler J and Heiss W-D (1996) Cerebral representation of one's own past: neural networks involved in autobio- graphical memory. Journal of Neuroscience, 16, 4275-4282.

Fletcher PC, Frith CD and Rugg MD (1997) The functional neuroanatomy of episodic memory. Trends in Neuroscience, 20, 213-218.

Gabrielli JDE, Brewer JB, Desmond JE and Glover GH (1997) Separate neural basis of two fundamental memory processes In the human medial temporal lobe. Science, 276, 264-266.

Gluck MA (1996) Computational models of hippocampal function in memory. Hippocampus, 6, 565-566.

Gluck MA, Ermita BR, Oliver LM and Myers CE (1997) Extending models of hippocampal function In animal conditioning to human amnesia. Memory, 5, 179.

Goldman-Rakie PS (1996) Regional and cellular fractionation of working memory. Proceedings of the National Academy of Sciences USA, 93, 13473-13480.

Goldman-Rakie P (1997) Space and time in the mental universe. Nature, 386, 559-560.

Golomb J, Kluger A, de Leon MJ, Ferris SH, Mittelman M, Cohen J and George AE (1996) Hippocampal formation size predicts declining memory performance in normal aging. Neurology, 47, 810-813.

Gordon B (1988) Preserved learning of novel information In amnesia: evidence for multiple memory systems. Brain and Cognition, 7, 257-282.

Graham K and Hodges J (1997) Differentiating the roles of the hippocampal complex and the neocortex in longterm memory storage: evidence from the study of semantic dementia and Alzheimer's disease. Neuropsychology, 11, 77-89.

Granger R, Wiebe SP, Taketani M and Lynch G (1996) Distinct memory circuits composing the hippocampal region. Hippocampus, 6, 567-578.

Greene J and Hodges J (1996) Identification of famous faces and famous names In early Alzheimer's disease: relationship to anterograde episodic and general semantic memory. Brain, 119, 111-128.

Hasselmo M (1994) Runaway synaptic modification In models of cortex: implications for Alzheimer's disease. Neural Networks, 7, 13-40.

Hasselmo ME, Wyble BP and Wallenstein GV (1996) Encoding and retrieval of episodic memories: role of cholinergic and GABAergic modulation in the hippocampus. Hippocampus, 6, 693-708.

Jansari A and Parkin AJ (1996) Things that go bump in your life: explaining the reminiscence bump in autobiographical memory. Psychology and Aging, 11, 85-91.

Jonker C, Launer L, Hooijer C and Lindeboom J (1996) Memory complaints and memory impairment in older individuals. Journal of the American Geriatrics Society, 44, 44-49.

Kapur N (1997) How can we best explain retrograde amnesia in human memory disorder? Memory, 5, 115.

Keane MM, Gabrielli JDE, Mapstone HC, Johnson KA and Corkin S (1995) Double dissociation of memory capacities after bilateral occipital-lobe or medial temporal-lobe lesions. Brain, 118, 1129-1148.

Kemperman G, Kuhn HG and Gago FH (1997) More hippocampal neurons in adult mice living in an enriched environment. Nature, 386, 493-495.

Knopman D and Nissen MJ (1991) Procedural learning is impaired in Huntington's disease: evidence from the serial reaction time task. Neuropsychologia, 29, 245-254. 
Knowlton BJ, Mangels JA and Squire LR (1996) A neostriatal habit learning system in humans. Science, 273, 1399-1401.

Markowitsch HJ (1996) Organic and psychogenic retrograde amnesia: two sides of the same coin? Neurocase, 2 , 357-371.

Mathews RC (1997) Is research painting a biased picture of Implicit learning? The dangers of methodologic purity In scientific debate. Psychonomic Bulletin Reviews, 4, 38-42.

McClelland J and Goddard N (1996) Considerations arising from a complementary learning systems perspective on hippocampus and neocortex. Hippocampus, 6, 654-665.

Mulligan R, Mackinnon A, Jorm AF, Giannakopoulos P and Michel JP (1996) A comparison of alternative methods of screening for dementia in clinical settings. Archives of Neurology, 53, 532-536.

Murre J (1997) Implicit and explicit memory in amnesia: some explanations and predictions by TraceLink Model. Memory, 5, 213.

Nyberg L, McIntosh AR, Houle S, Nilsson L-G and Tulving E (1996) Activation of medial temporal structures during episodic memory retrieval. Nature, 380, 715-717.

Perry RJ and Hodges JR (1996) Spectrum of memory dysfunction In degenerative diseases. Current Opinion in Neurology, 9, 281-285.

Reinkemeier M, Markowitsch HJ, Rauch M and KesslerJ (1997) Differential impairments in recalling people's names: a case study In search of neuroanatomical correlates. Neuropsychologia, 35, 677-684.

Ribot T (1881) Diseases of memory (in French). Paris: Germer Baillere.

Robbins TW (1996) Refining the taxonomy of memory. Science, 273, 1353-1354.

Ross GW, Abbott RD, Petrovitch H, Masaki KH, Murdaugh C, Trockman C, Curb JD and White LR (1997) Frequency and characteristics of silent dementia among elderly Japanese-American men. Journal of the American Medical Association, 277, 800-805.

Ruchkin DS, Johnson R, Grafman J, Canoune $\mathrm{H}$ and Ritter W (1997) Multiple visuospatial working memory buffers: evidence from spatiotemporal patterns of brain activity. Neuropsychologia, 35, 195-210.

Schmand B, Jonker C, Hooijer C and Lindeboom J (1996) Subjective memory complaints may announce dementia. Neurology, 46, 121-125.

Schmidtke K and Vollmer H (1997) Retrograde amnesia: a study of its relation to anterograde amnesia and semantic memory deficits. Neuropsychologia, 35, 505-518.

Schwartz BL, Hashtroudi S, Herting RL, Schwartz P and Deutsch SI (1996) d-Cycloserine enhances Implicit memory In Alzheimer patients. Neurology, 46, 420-424.

Selnes 0 (1995) Neuropsychological testing In clinical practice. Neurologist, 1, 273-283.

Smith GE, Peterson RC, lvnik RJ, Malec JF and Tangalos EG (1996) Subjective memory complaints, psychological distress, and longitudinal change in objective memory performance. Psychology and Aging, 11, 272-279.

Snowden J, Griffiths H and Neary D (1996) Semanticepisodic memory interactions In semantic dementia: implications for retrograde memory function. Cognitive Neuropsychology 13, 1101-1137.

Snowdon DA, Kemper SJ, Mortimer JA, Greiner LH, Wekstein DR and Markesbery WR (1996) Linguistic ability In early life and cognitive function and Alzheimer's disease in late life. Journal of the American Medical Association, 275, 528-532.

Starkstein S, Sabe L, Chemerinski E, Jason L and Leiguarda R (1996) Two domains of anosagnosia in Alzheimer's disease. Jounal of Neurology, Neurosurgery and Psychiatry, 61, 485-490.

Stern CE, Corkin S, Gonzalez RG, Guimaraes AR, Baker JR, Jennings PJ, Carr CA, Sugiura RM, Vendantham V and Rosen BR (1996) The hippocampal formation participates In novel picture encoding: evidence from functional magnetic resonance Imaging. Proceedings of the National Academy of Sciences USA, 93, 8660-8665.

Stuss D, Meiran N, Guzman A, Lafleche G and Willmer J (1996) Do long tests yield a more accurate diagnosis of dementia than short tests? Archives of Neurology, 53, 1033-1039.

Thompson RF and Kim JJ (1996) Memory systems in the brain and localization of memory. Proceedings of the National Academy of Sciences of USA, 93, 13438-13444.

Tierney MC, Szalai JP, Snow WG, Fisher RH, Nores A, Nadon G, Dunn E and St George-Hyslop SH (1996) Prediction of probable Alzheimer's disease in memoryimpaired patients: a prospective longitudinal study. Neurology, 46, 661-665.

Ungerleider L (1995) Functional brain imaging studies of cortical mechanisms for memory. Science, 270, 769-775.

Warrington EK and Cipolotti L (1996) Word comprehension. The distinction between refractory and storage Impairments. Brain, 119, 611-625. 


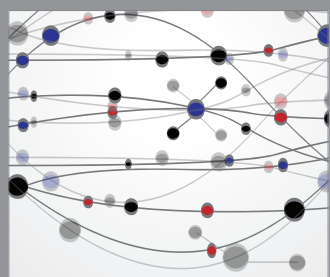

The Scientific World Journal
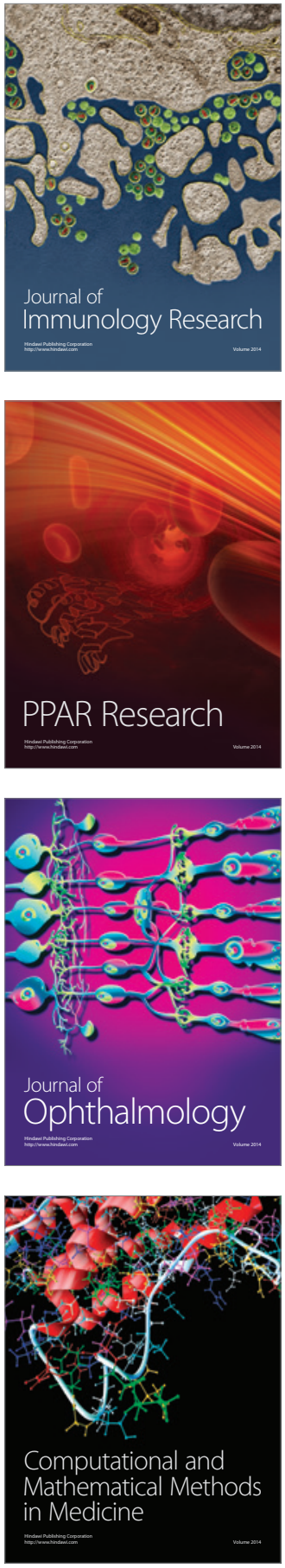

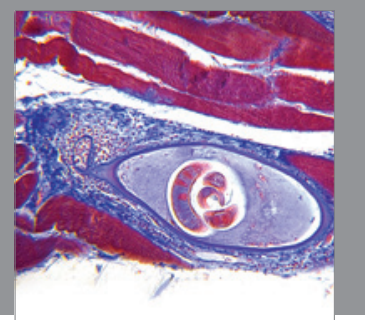

Gastroenterology

Research and Practice
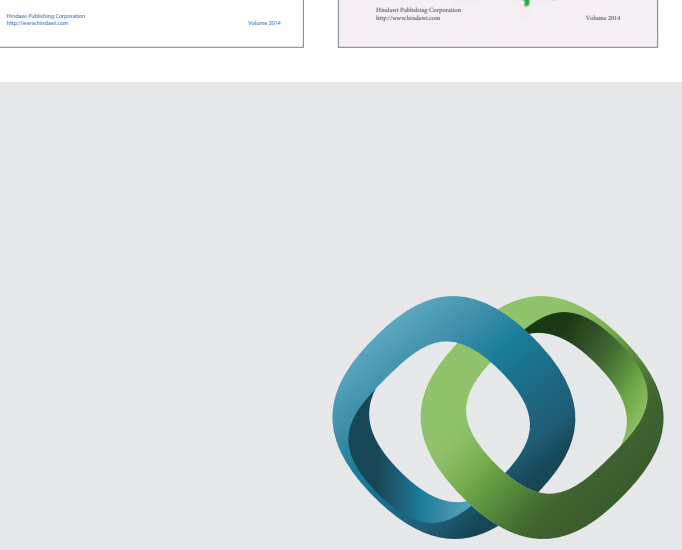

\section{Hindawi}

Submit your manuscripts at

http://www.hindawi.com
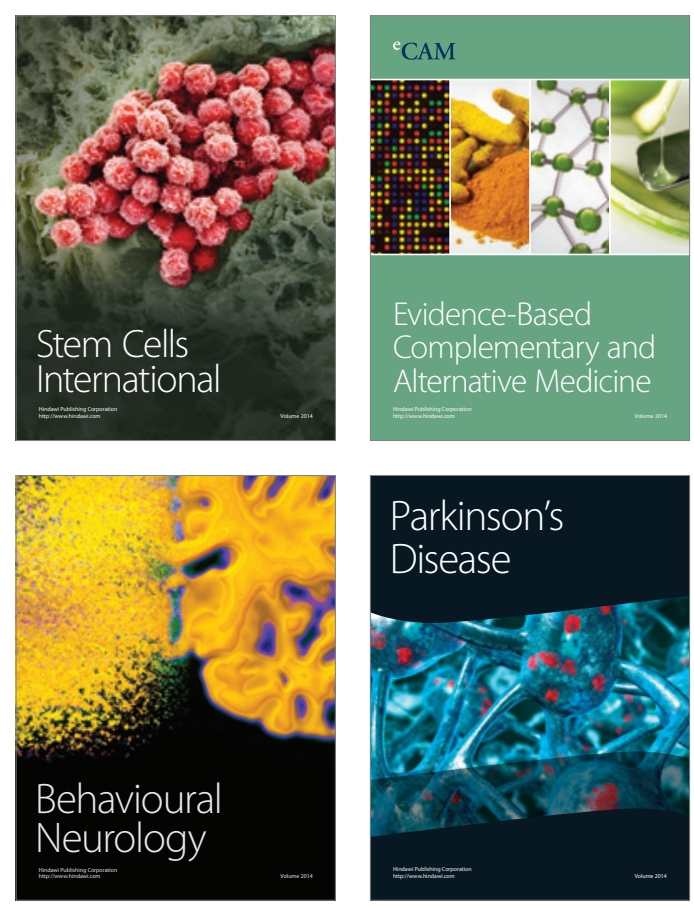

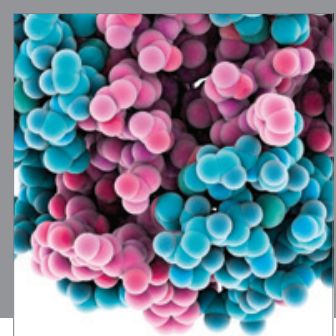

Journal of
Diabetes Research

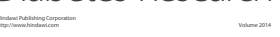

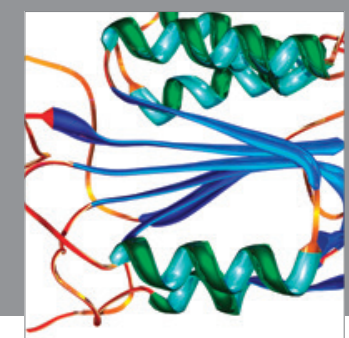

Disease Markers
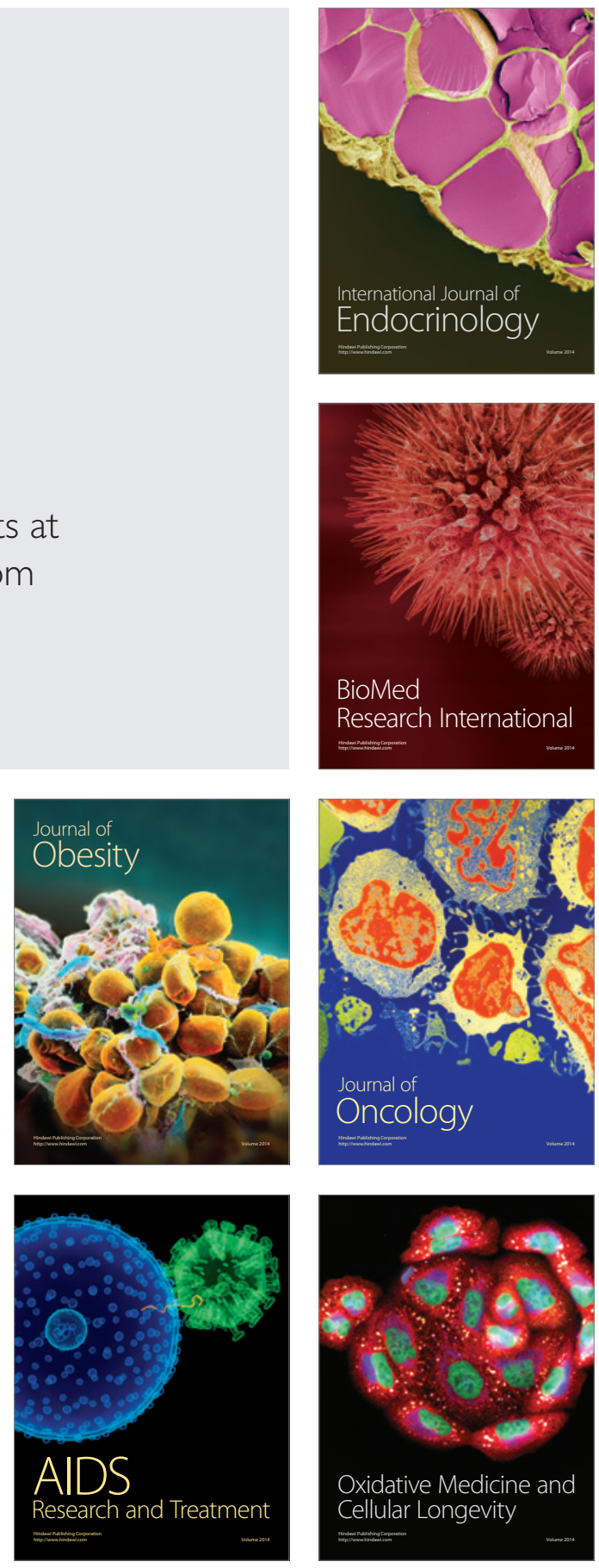